\title{
Homing in on a biological joint replacement
}

Farshid Guilak*

\begin{abstract}
The use of tissue engineering therapies for treating damaged articular cartilage has traditionally focused on cell-based therapies for the repair of focal chondral or osteochondral defects. A recent study by Lee and colleagues in the Lancet shows exciting proofof-concept that an acellular scaffold containing transforming growth factor beta 3 can induce homing of cells that regenerate a hyaline-like cartilage surface. These findings provide a glimpse into the possibility that tissue engineering may in fact provide the means for regeneration of an entire joint surface, beyond a simple focal defect in the articular cartilage.
\end{abstract}

Tissue engineering is a rapidly growing field that seeks to repair or regenerate injured or diseased tissues using combinations of cells, biomaterials, and biologically active molecules. With few exceptions, engineered tissues have been based on the use of autologous or allogeneic cells that have been removed from the body and then reintroduced following a variety of possible manipulations, such as cell expansion, exposure to growth factors, seeding in scaffolds, exposure to biophysical stimulation, or even genetic transfection.

These approaches have shown tremendous promise in the repair of many different tissues and organs, such as skin, cartilage, blood vessels, trachea, bladder, or bone (for example, [1-4]). Despite many rapid advances in the field, however, few tissue-engineered products are currently available in the clinical setting. One of the major hurdles in the commercialization of such approaches has been the complexity and, to a certain extent, the uncertainty of the regulatory pathway for ensuring the safety and efficacy of products that can involve combinations of cells, biomaterials, and growth factors [5-7]. Specific to cartilage repair, few techniques

*Correspondence: guilak@duke.edu

Departments of Orthopaedic Surgery and Biomedical Engineering, Duke University Medical Center, Durham, NC 27710, USA have been able to restore the functional mechanical properties of native articular cartilage in the joint [8].

In their ground-breaking study, Lee et al. [9] show a proof-of-concept that an acellular 'smart' scaffold can regenerate the articular surface of a rabbit synovial joint through induced homing of local cells using transforming growth factor (TGF) 33 . To create the scaffold, the morphology of the shoulder joint (proximal humerus) was recorded using a laser scanner, and an anatomically correct scaffold was created from poly( $\varepsilon$-caprolactone) and hydroxyapatite, in the shape of the joint surface. The scaffold was infused with TGF $\beta 3$-adsorbed collagen hydrogel. Four months after surgery, the scaffolds containing TGF $\beta 3$ were covered with hyaline cartilage with mechanical properties similar to those of native tissue. Importantly, the acellular scaffold had been repopulated by autologous cells that had then produced a hyaline-like cartilage layer. The source of the cells that regenerated the joint surface, although not definitively identified, appeared to be stem/progenitor cells in the synovium [10].

This study provides some of the first evidence that an acellular scaffold, loaded with the proper growth factor, can not only attract local cells to migrate into the scaffold, but also induce differentiation of those cells into a chondrogenic phenotype. By removing the need for exogenous cell seeding, Lee and colleagues have circumvented many of the steps associated with cell-based therapies, including cell isolation, seeding, and potential complications, such as disease transmission, immunogenicity, or tumorigenesis. In this respect, an acellular approach to tissue repair is likely to encounter fewer regulatory hurdles compared to a cell-based therapy.

In addition to the proof-of-concept that a single growth factor can be used to induce repopulation of an acellular scaffold with local progenitor cells, this study also highlights the importance and challenges in developing bioartificial technologies that can be used to regenerate entire joint surfaces. With few exceptions (for example, [11-13]), most tissue engineering approaches for cartilage regeneration have focused on the repair of focal defects in the joint surface. While approaches such as autologous chondrocyte implantation continue to show promise [3], the frequency of such isolated cartilage defects is significantly lower than the incidence of degenerative 
joint diseases such as osteoarthritis, which affect hundreds of millions of adults worldwide at a tremendous economic burden. Present treatment options for osteoarthritis are limited, and surgical management generally involves joint replacement with a metal and polyethylene prosthesis. While joint replacement is a well-established procedure, its relatively short lifespan makes this treatment unacceptable for younger or more active individuals, often requiring additional surgeries that involve progressively more complicated treatment with each joint replacement. Metal-on-metal joint prostheses showed early success as a novel means of joint resurfacing, but an increasing number of recent failures [14] has led to recalls of several such implants, further emphasizing the need for new technologies for treating degenerative joint disease.

Clearly, further study is needed to examine the feasibility of this technology in other joints, as well as its translation to the clinical setting. Nonetheless, the technique shown by Lee and colleagues provides a glimpse into the exciting possibility that tissue engineering may in fact provide a novel means for regenerating an entire joint surface, beyond a simple focal defect in the articular cartilage.

\section{Abbreviations}

TGF, transforming growth factor.

\section{Competing interests}

FG is the founder of Cytex Therapeutics, Inc.

Published: 14 December 2010

\section{References}

1. Naughton G, Mansbridge J, Gentzkow G: A metabolically active human dermal replacement for the treatment of diabetic foot ulcers. Artif Organs 1997, 21:1203-1210.

2. Macchiarini $P$, Jungebluth $P, G o T$, Asnaghi MA, Rees LE, Cogan TA, Dodson A, Martorell J, Bellini S, Parnigotto PP, Dickinson SC, Hollander AP, Mantero S,
Conconi MT, Birchall MA: Clinical transplantation of a tissue-engineered airway. Lancet 2008, 372:2023-2030.

3. Brittberg M, Lindahl A, Nilsson A, Ohlsson C, Isaksson O, Peterson L: Treatment of deep cartilage defects in the knee with autologous chondrocyte transplantation. N Engl J Med 1994, 331:889-895.

4. Atala A, Bauer SB, Soker S, Yoo JJ, Retik AB: Tissue-engineered autologous bladders for patients needing cystoplasty. Lancet 2006, 367:1241-1246.

5. Lee MH, Arcidiacono JA, Bilek AM, Wille JJ, Hamill CA, Wonnacott KM, Wells MA, Oh SS: Considerations for tissue-engineered and regenerative medicine product development prior to clinical trials in the United States. Tissue Eng Part B Rev 2010, 16:41-54.

6. Brevignon-Dodin L, Livesey F: Regulation of tissue-engineered products in the European Union: where are we heading? Regen Med 2006, 1:709-714.

7. Hellman KB: Engineered tissues: the regulatory path from concept to market. Adv Exp Med Biol 2006, 585:363-376.

8. Guilak F, Butler DL, Goldstein SA: Functional tissue engineering: the role of biomechanics in articular cartilage repair. Clin Orthop Relat Res 2001, 391:S295-305

9. Lee CH, Cook JL, Mendelson A, Moioli EK, Yao H, Mao JJ: Regeneration of the articular surface of the rabbit synovial joint by cell homing: a proof of concept study. Lancet 2010, 376:440-448.

10. De Bari C, Dell'Accio F, Tylzanowski P, Luyten FP: Multipotent mesenchymal stem cells from adult human synovial membrane. Arthritis Rheum 2001, 44:1928-1942.

11. Hung CT, Lima EG, Mauck RL, Takai E, LeRoux MA, Lu HH, Stark RG, Guo XE, Ateshian GA: Anatomically shaped osteochondral constructs for articular cartilage repair. J Biomech 2003, 36:1853-1864.

12. Ballyns JJ, Gleghorn JP, Niebrzydowski V, Rawlinson JJ, Potter HG, Maher SA, Wright TM, Bonassar LJ: Image-guided tissue engineering of anatomically shaped implants via MRI and micro-CT using injection molding. Tissue Eng Part A 2008, 14:1195-1202.

13. Woodfield TB, Guggenheim M, von Rechenberg B, Riesle J, van Blitterswijk CA, Wedler V: Rapid prototyping of anatomically shaped, tissueengineered implants for restoring congruent articulating surfaces in small joints. Cell Prolif 2009, 42:485-497.

14. Browne JA, Bechtold CD, Berry DJ, Hanssen AD, Lewallen DG: Failed metalon-metal hip arthroplasties: a spectrum of clinical presentations and operative findings. Clin Orthop Relat Res 2010, 468:2313-2320.

doi:10.1186/scrt40

Cite this article as: Guilak F: Homing in on a biological joint replacement.

Stem Cell Research \& Therapy 2010, 1:40. 